\title{
Regional energy markets and the cost of natural flow dam operation
}

\author{
F.T. Sparrow • P.V. Preckel • D.J. Gotham • \\ B.H. Bowen • Z. Yu
}

Received: 6 April 2011 / Accepted: 13 October 2011 / Published online: 6 November 2011

(C) The Author(s) 2011. This article is published with open access at Springerlink.com

\begin{abstract}
With the proliferation of electricity markets for the purchase and sale of firm and non-firm power and capacity, the possibility exists for using trade in these commodities to minimize the cost impact of operating dams to restore downstream flows to pre-dam patterns - so called Run of River (ROR) dam operation. We examine the impact of such markets on the incremental costs of ROR operation relative to least cost operation via a stochastic, dynamic optimization model. We identify features of the dam structure and of the economic environment that are critical to achieving ROR operation at modest incremental cost.
\end{abstract}

Keywords Run of river · Hydroelectric dam operation and capacity expansion · Stochastic optimization

\footnotetext{
The authors thank: (a) Gregory Thomas of the Natural Heritage Institute for first making us aware of the problem; (b) Dick Fisher of Voith Siemens Corporate Engineering in York, Pennsylvania for useful insights into the costs of adding generating units to existing hydro-electric structures; (c) Brian Shenk of the Army Corps of Engineers Hydropower Analysis Center in Portland, Oregon for making us aware of the work the Corps is doing in the evaluation of generating additions to existing facilities, in particular, to the Corps Libby Dam complex in Northern Montana; (d) Douglas G. Hall of the U.S. Department of Energy's Idaho National Laboratory's Wind and Hydropower Technologies Program for input on the discussion of Hydropower Capacity Increase Opportunities in the U.S.
}

F.T. Sparrow $(\bowtie) \cdot$ P.V. Preckel · D.J. Gotham

Energy Center at Discovery Park, Purdue University, 500 Central Drive, West Lafayette, IN 47907, USA

e-mail: fts@purdue.edu

B.H. Bowen

American University in Kosovo, Pristina, Kosovo

Z. Yu

EmberClear, Inc., Houston, TX, USA 


\section{Motivation}

By the end of the $20^{\text {th }}$ century, an estimated 50,000 large dams had been constructed worldwide for a variety of reasons, all significantly affecting upstream and downstream ecologies and communities [13]. While flood control, irrigation, recreation, and electric generation are acknowledged benefits of such dams, increasing concern in recent years has been voiced by those championing the negatively affected areas. Remedies for the degradation of the upstream and downstream environment range all the way from decommissioning and removal of the dams such as the Klamath river dam removal project in northern California and southern Oregon [9] to periodic flushing of the reservoir to move a portion of the accumulated sediment downstream and to restore the storage potential of the reservoir [27].

Environmental objectives for dam removal or modification generally include:

(a) preservation of unique downstream and upstream ecosystems, especially fisheries habitats, which include those protected by the controversial Endangered Species Act, such as the snail darter found below the TVA's now abandoned Tellico Dam project;

(b) maintenance of the livelihoods of communities and cultures both upstream and downstream of the dam sites - an estimated 2 million Chinese were moved from the floodplain of the Three Gorges Dam, eliminating 13 cities, 140 towns, and over a thousand villages and hamlets in the process [18];

(c) restoration of wetlands lost in downstream estuaries as a result of sediment being trapped in the dam reservoir, as well as wetlands submerged above the dam. While flood protection can help downstream environments, such protection comes at the cost of modifying, moving, and otherwise changing the nature of the wetlands. [26]

The question motivating this article is as follows. Are there ways of decreasing these degradation costs, yet preserving as much as possible the acknowledged dam benefits, particularly the low costs of electricity generation from such facilities? This problem is particularly important when it is realized that existing hydro-electric dams, which compose $10 \%$ of total generating capacity in the U.S. and $88 \%$ of renewable generation capacity in 2009, are among the cheapest means of storing electricity. This attribute grows in importance as the nation's priorities shift to employing intermittently available resources to generate electricity, most prominently wind and solar energy.

Consider also the fact that, we estimate an additional 20,000 MW of hydroelectric capacity - almost $20 \%$ of existing hydro capacity - remains undeveloped in the U.S. As the nation strives to rid itself of dependence on either foreign natural gas or domestic coal for power generation, the ability to construct these new facilities in order to minimize environmental damage becomes ever more important.

Put in an optimization context, can environmental objectives be included in the formulation of least cost operating plans for hydro-electric facilities? The literature on inclusion of environmental objectives in the optimization of releases from hydroelectric generation facilities has a history dating back at least to 1982, when Sale proposed using chance constrained linear programming to predict their impact [23]. 
Since then many articles and two reviews $[12,14]$ have appeared, which is a testimony to the continuing importance of the topic.

In one of the surveys, [14] proposed that the literature could be classified as to how the goals of the environmental objectives were entered into the optimization of releases by adding to the least-cost operation problem: (a) water quality constraints, such as minimum flows; (b) constraints that force the mimicking of natural pre-dam flows; or (c) constraints based on downstream riverine population models. In this paper, we use approach (b), in that we assume the environmental objectives are achieved if the dam releases are timed so that inflows equal outflows-so called "Run of River" (ROR) operation of the dam, recognizing that there are those who question if a natural flow regime [20] restoration is necessarily the best solution to satisfying such objectives [14, p. 345].

Our objective is to identify ways to minimize the increase in electricity cost caused by imposition of ROR operating rules on dams, using a long-run electric generation optimal capacity expansion and operation model that incorporates stochastic electricity demand, cost, and water availability elements in the calculation. Particular attention is paid to the impact on such cost increases caused by the emergence of multiple markets for both electricity (firm, non-firm and capacity) and natural gas (forward and spot). Other papers have calculated the short run (capacity fixed) cost of imposing environmental release rules on dam operation (Harpman [11]; Edwards et al. [4]; Guan et al. [10]; Kotchen [15]), but to our knowledge, only one other paper [11] has investigated ways the capacity of the dam structures might be altered to minimize the incremental costs of ROR operation. In this paper, this incremental cost is taken to mean the additional cost to the system operators of changing the output of the hydroelectric system by a given increment relative to least cost operation. The total excludes any environmental/social costs or benefits of system operation, and any recovery of sunk costs incurred in the construction of the existing system. It includes the annualized costs of expanding the capacity of the generating system when such expansion is necessary for cost minimization.

Certainly, the quantitative answer as to what mix of alternatives will minimize the incremental cost of ROR operation can only be accomplished by a detailed, case by case engineering analysis. However, situations where such costs are likely to be within reasonable limits and those where costs are likely to be prohibitive can be identified by means of a stylized stochastic model of the dynamic operation of mixed thermal-hydroelectric system.

\section{Paper summary}

Two earlier papers described such a model [21] and presented the results of a series of model runs applying the model to the operation of the Akosombo Dam complex in Ghana [22]. These papers showed that in theory the ROR incremental cost penalty could be 0 , if (a) perfect markets exist for the external purchase and sale of electricity, (b) sufficient excess hydro generating capacity exists to handle the highest inflow rates, and (c) sufficient transmission capacity exists to handle the increased power purchases and sales necessary to the regional grid. What these conditions amount 
to is the creation of a "virtual" water reservoir in the form of markets where excess electricity can be sold in the wet months, the money banked, and then used to buy electricity in the dry season. However, since such conditions seldom if ever exist in the real world, ROR operating penalties will be excessive in most, but it turns out, not all instances.

This paper expands on a conclusion drawn from the second paper-that the prime factors determining the incremental cost of switching from a cost minimization rule of operation of a hydroelectric complex to an ROR rule are: (1) access to external markets for electricity purchase and sale and (2) presence of a relatively cheap method of increasing the capacity of the hydroelectric generators at the dam site.

The main point is that given the proliferation of traded electricity commodities (firm power, non-firm power, capacity, etc.) in recent years, the existence of these multiple markets creates, in certain circumstances, an opportunity to operate dam complexes in an ROR mode without great economic penalty. Of course, these incremental costs must be balanced with the environmental benefits of ROR operation to achieve a net gain, and situations where the benefits are large relative to even substantial incremental ROR costs could still be worth pursuing.

\section{Model description}

We formulate a stochastic programming model with an objective of minimizing the sum of operating and levelized new investment costs of meeting energy and peak demand in a representative year. The year consists of two seasons labeled wet and dry. Within each season, the model can have any number of time period sub-divisions (e.g. weeks, months, etc.) depending on the desired accuracy of spillage and water turbine productivity patterns, the time detail of the available hydrologic data, and the available computing resources. In the experiments below, a single period is chosen for both the wet and dry seasons to illustrate the use of the model. Increasing the number would add substantially to the computer time necessary to solve the problem, since in the model described below, the calculations would have to be done for 25 to the $n$th power cases for $n$ periods. The choice of using a representative year in the analysis, rather than explicitly modeling as well the year by year path to such a representative year, needs some explanation.

First, it should be recognized that we explicitly take into account the uncertainty associated with conditions in the representative year. We determine the cost minimizing response to that uncertainty regarding fuel prices ( 3 scenarios), demands ( 3 scenarios), and weather conditions in the wet season (5 conditions) and dry season ( 5 conditions) for a total of 225 representative year types, taking into account in the optimization probability estimates of each scenario.

What we do not model is the uncertain path to each of these 225 scenarios over the years intervening between the present time and the representative year, which, as we describe below, is far enough in the future for all capacity expansion decisions to be implemented save one-the capacity of the reservoir itself, which we assume is fixed at its current level.

Two decision variables in the model tie together one year to the next leading up to the representative year in the model-the capacity expansion of the generating units, 
and the opening water level of the reservoir. Consider first the capacity expansion pattern. By choosing the representative year approach, we assume it makes no difference what the capacity expansion time pattern was that led to the number of units chosen to be installed by the representative year. They could be spread out evenly over the interval, or irregularly in response to the varying demand conditions during the time period between "now" and the beginning of the representative year. The problem is that most projections of electricity demand growth assume smooth growth throughout the planning horizon, thus giving us no information regarding the irregularity of the growth pattern, and thus no information to populate a multi-year growth model of the type that might be constructed. It is our opinion that the factors that make the time pattern of capacity accumulation-scale economies, non-linear growth rates, and the like, that require explicit modeling of the trajectory, as in Manne's classic work [17] are not relevant for our purposes in this paper.

The path of water accumulation in the opening inventory of the reservoir is quite a different situation. By choosing the opening level only, we ignore the possible impact of, among other things, multi-year droughts and floods that could have taken place on the way to accumulating the desired level. It is quite conceivable that the path to the opening reservoir level may well be a major determinant of the level itself. The occurrence of say, three consecutive drought years, as opposed to three years spread out over the interval, might well result in irreparable harm to the economy and threaten the very existence of the hydro complex itself.

While recognizing this potential problem we argue that data regarding estimates of the various climate trajectories are simply not detailed enough to support such an analysis. And even if they were, the computational complexity of adding climate trajectories and intervening year decisions regarding opening water levels and yearly release patterns would overwhelm most computers. If the model contained $N$ intervening years, then the model would have to consider 225 to the $N$-th power trajectories. This exponential growth of the model is the well known stochastic programming "curse of dimensionality." While others (e.g. Emmet [6]) have proposed methods of reducing the curse of dimensionality in dealing with exactly this aspect of climate uncertainly in the operation of reservoir systems, we have opted to focus more closely on the representative year. Ideally, this model should be complemented with other models that focus on the transition from the current situation to the representative year.

The analysis is intended to be for an existing hydroelectric facility. The representative year is far enough in the future to allow for construction of additional thermal units, addition of hydro generation capacity to existing dam structures, and readjustment of the water levels in the reservoir, but not far enough to adjust the working capacity of the reservoir. Construction completion times for additional thermal and hydro electricity units added to existing structures are on the order of 7-10 years, while dam containment and capacity modification lead times (including site studies) can easily be twice that, involving changing maximum reservoir levels and thus changing the shoreline of the reservoir. Access to regional markets for the forward purchase of fuel for the thermal units, and spot sale and purchase of fuel are model options. In addition, regional markets for the purchase of firm and non-firm electricity (MWh) as well as purchase and sale of capacity (MW) are available as options in 
the model. A complete mathematical statement of the model equations and variables can be found in the Appendix.

In the model, the fundamental investment decision prior to the start of the representative year is to determine the level of investments in new generating facilities and initial stored water in the reservoir that will minimize the cost of electricity production over the representative year. These decisions will differ, depending on whether or not the system is run in the cost minimization or ROR mode. This calculation will trade off the increased annualized investment costs of the new generation equipment versus the decrease in operating costs. When the system is run in ROR mode, this includes the additional annualized costs of meeting demand from thermal, rather than hydro units caused by allowing the dam releases to follow the natural hydrograph of the river.

When following least cost operating rules, the fundamental operating decision the model makes during the representative year is the amount of water to accumulate in the reservoir during each period of the wet season for use in the dry season, and the optimal volume and timing of release of that water in the dry season. Too much water stored means reduced hydro generation during the wet season, which means high thermal generation expenses during the wet season. Too much water stored also runs the risk of reservoir spillage and the waste of "free" electricity, in case of a scenario with very high inflows. Too little water stored means high thermal generation operating costs and a need for more thermal generating capacity in the dry season, particularly if a drought scenario takes place. When following ROR operating rules, no water storage optimization is possible. This mode of operation is enforced by imposition of constraints that require outflows to equal inflows in all periods.

Four major relationships govern the model's behavior:

(1) The water balance equation, which requires that for all scenarios and periods the ending water volume equals the opening volume plus inflows minus discharge through the turbines minus any spillage which takes place.

(2) The electric energy ( $\mathrm{kWh}$ ) demand/supply balance equation, which requires that for all scenarios and periods demand must be met by either thermal generation, hydro generation, distributed generation (modeled as high cost, limited capacity, small scale diesel powered generators operated by end-users), purchase or sale of firm or non-firm electricity, or if all else fails, unmet demand in the form of rolling blackouts, etc. Unmet demand is costed in the model at $\$ 1 / \mathrm{kWh}$, which is about 20 times the normal cost of electricity and well above the cost of distributed generation which ranges from 10 to 20 cents/kWh, depending on fuel cost and climate scenarios.

(3) The electricity capacity $(\mathrm{kW})$ demand/supply balance equation, which requires for all scenarios and periods that the peak capacity requirements plus a specified reserve margin must be met by either thermal or hydro capacity or the purchase (net of sales) of capacity or firm electricity on the grid market.

(4) The water turbine input per unit of generation factor, measured in $\mathrm{ft}^{3} / \mathrm{MWh}$, relates the volume of water retained in the reservoir to the number of cubic feet of water flowing through the turbines necessary to produce one MWh of electricity. This relationship is vital to the correct functioning of the model, since the cubic feet required to produce one MWh provides the link between the water balance 
equation and the electricity balance equation. This highly non-linear relationship combines into one function the relation between water volume and head, a function heavily dependent on the contours of the specific reservoir, and the universal relation between head and water productivity, governed by well known hydrologic principles. The turbine input per unit of output factor enters the water balance equation described in (1) above as a conversion factor, converting the $\mathrm{MWh}$ generated by the hydro units, a decision variable, into the $\mathrm{ft}^{3}$ of water withdrawn from the reservoir during generation. The result is the water balance equation contains the product of two decision variables, the volume of the reservoir embedded in the water productivity term, and the electricity generated by the dam's turbines. While this complicates the computation of the least cost solution to the problem, the difficulty can be overcome by using an iterative scheme described below in the Mathematical Appendix.

The model proceeds in a series of five stages separated in time. Table 1 illustrates the timeline. Three sets of random variables are sequentially realized. Stage I takes place seven years in advance of the beginning of the representative year-enough time in advance of the representative year to complete the purchase and installation of any new generation or transmission equipment, including dam retrofits. In Stage I, the model determines the amount and type of additional thermal and hydro generation and transmission capacity that will be added for use during the representative year. Further, knowing the water level currently in the reservoir, the model solution determines a target level of water storage to serve as the opening water inventory for the representative year's operation. These decisions are made with knowledge of the equipment costs and the expected revenues forgone associated with increasing water storage. However these Stage I decisions are made with only probabilistic knowledge of the demand growth scenarios (for both energy and peak demand), which is realized prior to the representative year; the forward price of fuel; firm electricity prices; and electricity capacity costs expected at the beginning of the representative year (all indexed by price and growth scenario " $h$ "); the weather-sensitive water inflows to the dam; demands; and spot fuel prices that will prevail during the wet season of the year (indexed by scenario " $w$ "), and the weather sensitive scenarios for the dry season (indexed by scenario " $d$ ").

Between Stages I and II, construction of any new hydro and thermal capacity, and water accumulation within the dam impoundment takes place. The construction costs and opportunity costs of the forgone hydro generation revenue, associated with filling the reservoir, are incurred, which are the Stage I contributions to the model objective function. In addition, the price and demand growth scenario " $h$ " for the first set of random variables is realized. As is typical in this type of dynamic and stochastic model, decisions in subsequent stages are made conditional on the outcomes of the random variables in earlier stages. Thus, Stage II decisions are made conditional on the outcomes of the random variables realized between Stages I and II. The decisions in later stages are also made conditional on the decisions made in earlier stages. (Because the decision variables beyond the first stage are conditional on both decisions that have been made in prior stages and any random variables that have been realized by the current stage, these are often called recourse variables.) Thus at the beginning 
Table 1 Timeline of model events

\begin{tabular}{|c|c|c|c|c|}
\hline Stage & When Stage & Decisions & $\begin{array}{l}\text { Info Known with } \\
\text { Certainty }\end{array}$ & $\begin{array}{l}\text { Info Known Only with } \\
\text { Probabilities }\end{array}$ \\
\hline I & $\begin{array}{l}\text { Well in } \\
\text { advance of } \\
\text { the repre- } \\
\text { sentative } \\
\text { year }\end{array}$ & $\begin{array}{l}\text { All integer investment } \\
\text { decisions for new hydro } \\
\text { and thermal } \\
\text { construction; target } \\
\text { water volume in } \\
\text { reservoir, a continuous } \\
\text { variable, as are all the } \\
\text { remaining variables in } \\
\text { all succeeding stages }\end{array}$ & $\begin{array}{l}\text { Investment costs, current } \\
\text { volume in the reservoir, } \\
\text { lost revenues/unit water } \\
\text { added to reservoir }\end{array}$ & $\begin{array}{l}\text { Demand growth and wet } \\
\text { season forward gas, electric } \\
\text { capacity, and electric firm } \\
\text { price scenario "h". Wet } \\
\text { season scenario "w" } \\
\text { parameters. Dry season } \\
\text { forward fuel, electric firm } \\
\text { and capacity price Dry } \\
\text { season scenario "d" } \\
\text { parameters }\end{array}$ \\
\hline II & $\begin{array}{l}\text { At } \\
\text { beginning } \\
\text { of wet } \\
\text { season }\end{array}$ & $\begin{array}{l}\text { Forward fuel, electricity } \\
\text { capacity and firm } \\
\text { electricity purchases for } \\
\text { wet season }\end{array}$ & $\begin{array}{l}\text { All investment } \\
\text { decisions, opening water } \\
\text { inventory; all constants } \\
\text { associated with scenario } \\
\text { 'h'-peak demand, } \\
\text { demand growth; forward } \\
\text { fuel purchase, electric } \\
\text { capacity, and firm } \\
\text { electric prices }\end{array}$ & $\begin{array}{l}\text { Wet season scenario "w" } \\
\text { parameters. Dry season } \\
\text { forward fuel, electric firm } \\
\text { and capacity price. Dry } \\
\text { season weather scenario } \\
\text { "d" parameters }\end{array}$ \\
\hline III & $\begin{array}{l}\text { During wet } \\
\text { season }\end{array}$ & $\begin{array}{l}\text { Wet season recourse } \\
\text { variables for each } \\
\text { period-thermal and } \\
\text { hydro generation, spot } \\
\text { purchase/sale of gas, } \\
\text { non-firm electricity, } \\
\text { distributed generation, } \\
\text { unmet demand, dam } \\
\text { spills, ending water } \\
\text { inventory }\end{array}$ & $\begin{array}{l}\text { Wet season period } \\
\text { weather scenarios up to } \\
\text { and including current } \\
\text { period-inflows, } \\
\text { demands, spot gas } \\
\text { sale/purchase prices, } \\
\text { non-firm electricity } \\
\text { prices, previous period } \\
\text { water inventory }\end{array}$ & $\begin{array}{l}\text { Dry season forward fuel, } \\
\text { electric firm and capacity } \\
\text { prices. Dry season weather } \\
\text { scenario "d" parameters }\end{array}$ \\
\hline IV & $\begin{array}{l}\text { At } \\
\text { beginning } \\
\text { of dry } \\
\text { season }\end{array}$ & $\begin{array}{l}\text { Forward fuel and firm } \\
\text { electricity purchases for } \\
\text { dry season }\end{array}$ & $\begin{array}{l}\text { Forward dry season fuel } \\
\text { and firm electric prices } \\
\text { plus all above }\end{array}$ & $\begin{array}{l}\text { Dry season weather } \\
\text { scenario "d" parameters }\end{array}$ \\
\hline \multirow[t]{2}{*}{ V } & $\begin{array}{l}\text { During dry } \\
\text { season }\end{array}$ & $\begin{array}{l}\text { Dry season recourse } \\
\text { variables for each } \\
\text { period-thermal and } \\
\text { hydro generation, spot } \\
\text { purchase/sale of gas and } \\
\text { non-firm electricity, } \\
\text { distributed generation, } \\
\text { unmet demand, dam } \\
\text { spills, ending water } \\
\text { inventory }\end{array}$ & $\begin{array}{l}\text { Dry season period } \\
\text { weather scenarios up to } \\
\text { and including current } \\
\text { period-inflows, } \\
\text { demands, spot gas } \\
\text { sale/purchase prices, } \\
\text { non-firm electricity } \\
\text { prices }\end{array}$ & Everything known \\
\hline & & & $\begin{array}{l}\text { Previous period water } \\
\text { inventory }\end{array}$ & \\
\hline
\end{tabular}


of Stage II, the amount of thermal and hydro capacity that has been added, the opening level of water in the reservoir, gas forward price, electricity firm prices, electricity capacity prices, and the initial level of demand are all known.

In Stage II, the model determines how much fuel to purchase in the wet season forward market, the amount of firm power (MWh) to purchase in the regional markets, and the amount of capacity (MW) to buy or sell in the regional capacity markets to meet peak demand in the wet season. Stage II is at the beginning of the wet season; so, all of these decisions are made with only probabilistic knowledge of the actual wet season weather conditions and spot gas and electricity non-firm purchase/sale prices that will take place. Since it is assumed that peak demand takes place in the wet season, rather than the dry, the only peak demand constraint in the model is in the wet season.

Between Stages II and III, the outcomes of the second set of random variables, the weather scenarios " $w$ " for the wet season, become known. Hence in Stage III, decisions are made with knowledge of water inflows during the season, the energy demand for electricity, and spot fuel and non-firm electricity selling/buying prices (as well as the realizations of random variables and decisions that precede the Stage III decisions).

In Stage III, wet season recourse variables for the wet season scenarios are selected to meet electric energy demand, including gas market spot purchases, sales of excess forward market gas, thermal and hydro generation, distributed generation, non-firm electricity purchases/sales, and if all else fails, incurring a shortage cost for unmet demand. Also during the periods in Stage III, the water inflows associated with the scenario in that period become known, and the recourse variables for the water balance equation-water outflows associated with hydro generation, ending inventory of water in the reservoir, and spillage - are selected to ensure that the water balance equation is respected. Spillage can take place in two ways-limited capacity spillage through tunnels well below the reservoir lip, if such flood tunnels are available, and unlimited spillage over the spillway when the reservoir is full. Without using such tunnels or filling the reservoir to spill level, it is generally impossible for the dam to discharge the inflow volume during flood periods due to the limited water flow capacity of the water turbines.

In Stage IV (at the beginning of the dry season), in advance of knowledge of the dry season weather, but knowing the amount of water left in the reservoir from the wet season and dry season forward market fuel prices, the level of forward gas purchases for the coming dry season is decided, as well as the amount of firm electricity to buy or sell for the coming dry season.

Between Stages IV and V, the outcomes of the third and final set of random variables, the weather scenarios " $d$ " for the dry season, become known. Hence, decisions in Stage $\mathrm{V}$ are made conditional on the outcomes of all of the random variables as well as on all decisions made in Stages I-IV.

In Stage V, dry season recourse variables, which are conditional on the dry season weather scenarios, are selected to meet electric energy demand. These decisions are: gas market spot purchases, sales of excess forward market gas, thermal and hydro generation, distributed generation, non-firm electricity purchases/sales, and failing all else incurring the shortage cost of unmet demand. To insure sustainability of the 
water management plan, the value of the dry season ending water inventory must equal the wet season opening volume in every instance of the outcomes for the three sets of random variables.

The objective function to be minimized is the sum of the annualized cost of Stage I capacity additions made to the system and electricity sales forgone by any increase in the reservoir level, plus all Stages II-V gas and electricity (energy and capacity) purchase costs less revenues from the sale of any excess. The time periods, decisions, and what is known with certainty and probabilistically at each of the decision points is summarized in Table 1.

Measuring the cost increase caused by switching to the ROR mode of operation is accomplished by comparing the results of the cost minimization model, where the variables are set to minimize costs, with the cost of the system if the sum of water releases for hydro generation and spillage is set equal to each scenario's water inflows, with all other variables set to minimize cost.

\section{Model data}

Data used to populate the model are from three sources.

DATA SET 1 All data in this category are taken from estimates of the characteristics of Ghana's Akosombo/Kpong complex, and discussed in Preckel et al. [21, 22]. These data include:

(a) The capacities of the existing thermal units (two $110 \mathrm{MW}$ combustion turbines and three $110 \mathrm{MW}$ combined cycle generators with all assumed to be available 75 percent of the time);

(b) The existing transmission capacity of the lines connecting the region to its neighbors $(400 \mathrm{MW})$, with an option to double this capacity at a cost of $\$ 67 / \mathrm{kW}$;

(c) The capacity of the natural gas delivery system for the thermal units (210 billion standard cubic feet per day);

(d) The maximum working capacity of the reservoir (5,200 billion cubic feet);

(e) The relationship between the volume of water in the reservoir and turbine productivity. This is the water input/unit of output for the water turbines for various reservoir volumes, which is assumed to be a rectangular hyperbolic function truncated at the minimum and maximum possible reservoir volumes. In the model, a piecewise linear approximation to the relationship is based on data points relating reservoir volume to turbine productivity taken from early Volta River Authority annual reports.

(f) The MW capacities of the existing hydro units in the complex (0.979E3 MW for Akosombo and 0.142E3 MW for Kpong);

(g) The characteristics of the spillage system of the dam (gated or non-gated, spillway durability);

(h) The initial level of the reservoir at the time of planning the expansion of capacity (2,909 billion cubic feet);

(i) Electricity demand and demand growth data for both energy (MWh) and capacity (MW) in the regions served by the dam complex. During the wet season, 
these are taken to be 6,180 thousand MWh energy and 2,003 MW peak including a 10 percent reserve margin, respectively, based on normal growth scenario for the representative year and 90 percent of these amounts during the dry season. The low and high growth scenarios are $85 \%$ and $112 \%$ of normal growth, based on historical estimates of regional growth patterns; scenario probabilities are $22 \%, 56 \%$, and $22 \%$ for the low, medium, and high growth scenarios, again based on historical data. The numbers for energy in peak demand conditional on demand growth scenario and weather may be found in the model formulation at http://www.purdue.edu/ discoverypark/energy/assets/pdfs/RORModelJune2009.pdf.

(j) The five wet and dry season water inflow scenarios-flood, wet, normal, dry, and drought - and their probabilities were based on an examination of the wet and dry season inflows into Lake Volta during the period 1961-1990, as reported by the ADAPT project [1].

DATA SET 2 All data in this category are for expansion possibilities and come from a variety of sources as cited. Two types of thermal units can be added to the generation system-110 MW simple cycle units costing $\$ 527 / \mathrm{kW}$ with a heat rate of $11,280 \mathrm{Btu} / \mathrm{kWh}$, which are available 85 percent of the time [8]; and $330 \mathrm{MW}$ combined cycle units costing $\$ 800 / \mathrm{kW}$ with a heat rate of $7,260 \mathrm{Btu} / \mathrm{kWh}$, also available 85 percent of the time [8]. Three types of hydroelectric units can be added to the dam complex: (a) $170 \mathrm{MW}$ units that can be added to the dam face at a cost of $\$ 2,470 / \mathrm{kW}$ if no provision was made for their addition at the time of original construction of the dam (estimate based on the original cost of the Akosombo complex built in 1961 inflated to 2009 dollars) and at a cost of $\$ 700 / \mathrm{kW}$ if such provision was made (based on the cost of installing a fifth $500 \mathrm{MW}$ generating unit in one of two empty bays at BC Hydro's Revelstoke Station in Camloops, BC [2]); (b) small 26 MW ROR units that can be added to the top of the spillway of the dam and to the existing ROR facility at Kpong at a cost of $\$ 1,615 / \mathrm{kW}$ [7]; (c) small $26 \mathrm{MW}$ high head generating units and penstocks that can be added to the face of the spillway at a cost of $\$ 3,600 / \mathrm{kW}$ [24]. The Akosombo reservoir level must be raised to the spill level for options (b) and (c) to operate, resulting in a one-time charge equal to the annualized cost of the electricity revenues foregone caused by increasing the storage volume. A capital recovery factor of 12 percent is assumed for all plants constructed for the system.

DATA SET 3 A challenging part of populating the model with realistic data is the specification of an approximate stochastic process for prices for forward and spot trade in natural gas, firm and non-firm power, and capacity. Spot gas buying and selling during the wet and dry seasons serve as recourse variables for forward gas purchases made prior to both seasons. Non-firm electricity purchases and sales during the wet and dry seasons serve as recourse variables for firm electricity purchases made prior to the respective seasons. Firm electricity sales in both seasons serve as recourse variables for generation capacity installed prior to the beginning of the representative year.

Since "make or buy" decisions for electricity are central to the model, the relation between this price structure and the costs assumed for the production of thermal 
electricity in the model needs to be carefully specified. The model assumes that the selling prices of firm and non-firm electricity and capacity are based on the costs of production in plants operated by the utility. Purchase costs are based on the same production costs, plus a fixed mark-up. Firm power purchases are not simply bundled non-firm and capacity purchases, since firm power must be purchased prior to knowledge of the weather scenario, while non-firm power purchases are decided upon after weather scenarios are known. The model is designed to prevent power wheeling, i.e. the simultaneous buying and selling of electricity in a single scenario, to avoid the possibility of limitless arbitrage between the capacity, firm, and non-firm markets.

Regarding gas prices, Luenberger [16], argues that the expected price in investors' minds now, at time 0 , of the spot market price of a commodity at time $T$ in the future, $\mathrm{E}_{0}[S(T)]$, should be equal to the observed forward price now at time 0 for a contract for delivery at the same time $T, F_{0}(T)$. Thus, the current forward price for delivery at $T$ is a good estimator for the price investors are expecting to pay for gas in the spot market at $T$. This is because speculators can be expected to respond to any inequality, since the commodity and the time of payment are the same for the forward and spot contracts. (On the other hand, Pindyck [19] argues $\mathrm{E}_{0}[S(T)]$ and $F_{0}(T)$ will be equal only if there is no risk premium. Since this is unlikely, Pindyck argues that since holding the commodity entails risk, "investors would expect that over the holding period, the spot price will rise above the current futures price." In what follows, the Luenberger convention will be used.)

Regarding the relationship between the observed forward price now at time 0 for delivery at time $T, F_{0}(T)$, and the observed spot price now at time $0, S(0)$, the literature agrees that the current forward price should be equal to the current spot price times $(1+r) \exp (T-t)$ where $r$ denotes the interest rate, $t$ is the point in time when the futures contract is available for purchase, and $T$ is the delivery date. Since the forward price in the model precedes the spot price by one half year, and assuming the discount rate is 10 percent/year, we have that the current forward price for delivery in one half a year approximately equals 1.05 times the current spot price. Sale of excess gas in the spot market is assumed to be 15 percent below the cost of purchase in spot markets. (For example, if the purchase price of gas in the wet season forward market was \$4.32/MMBtu, the delivered price to industrial customers in the U.S. in May 2009, then the wet season spot gas purchase price would be identical, the dry season forward price would be 5 percent higher at $\$ 4.54 / \mathrm{MMBtu}$, as would the dry season spot price. Spot gas sales for the wet and dry period would be 15 percent less, or $\$ 3.67$ and $\$ 3.86 / \mathrm{MMBtu}$, respectively.)

Thermal firm electricity purchase costs are based on the fixed and variable operating costs for the $330 \mathrm{MW}$ advanced combined cycle units contained in the model operating at capacity, plus an 18 percent markup over costs. In addition, the capital recovery factor is assumed to be 15 percent, rather than 12 percent to reflect the higher risk associated with building for sale in the open market. Forward gas is assumed to be purchased for use for generating firm electricity and spot gas for non-firm electricity, since forward gas and firm electricity contracts are both negotiated prior to the beginning of the wet and dry seasons. (Scenario variations in the prices for gas (forward and spot) and electricity (firm energy and capacity, as well as spot) are determined using the following rules; (a) minus/plus 20 percent for the low and high 
price scenarios; (b) minus/plus 10 percent and 20 percent for flood, wetter, dry, and drought weather conditions.)

The price of purchased capacity to meet reserve requirements is assumed to be equal to the cost of new entry (CONE) value recently suggested by the Midwest Independent System Operator (Megawatt Daily, 2008). The CONE value is based on the annualized construction costs of combustion turbines, and is set at $\$ 80 / \mathrm{kW} / \mathrm{yr}$. It is assumed that no half year contracts for capacity are available in the capacity market, only full year contracts. Thus, purchases and sales of capacity are made only during the wet season, and such purchases and sales help satisfy both wet and dry season reserve requirements. In all cases, sale prices are assumed to be 85 percent of purchase costs. (For example continuing the previous example, if the spot and forward wet market gas purchase prices were both $\$ 4.32 / \mathrm{MMBtu}$, the delivered price to U.S. industrial customers in May 2009, [5], and the price used in the normal wet season scenario in the model, then the wet season non-firm electricity price would be $\$ 4.32$ times the heat rate of the combined cycle unit 7,260 Btu/kWh or 3.14 cents per $\mathrm{kWh}$, plus an assumed markup of 18 percent, or 3.71 cents/kWh. Spot sales would be simply 3.14 cents/kWh. Firm electricity would cost 3.71 cents/kWh plus the annual fixed cost of the plant using a capital recovery factor of 15 percent, $\$ 120 /$ year, divided by 7746 hours, the operating capacity of the plant, or 1.61 cents/kWh, plus the markup, or 1.9 cents/kWh, for a total of 7.22 cents/kWh. Dry season firm and non-firm purchase and sale prices would be higher to reflect the higher gas prices in the dry season.)

\section{The experiments}

There are four experiments. The key differences between these experiments relate to the possibilities and costs for retrofitting the dam to add hydro units and whether markets are available for firm power, non-firm power and capacity. Specifically, the experiments are based on combinations of the following features.

\subsection{Retrofit cost of hydro units on the face of the existing dam structure}

Dam Scenario I No provision was made at the time of initial construction to add additional penstocks and generators to the existing dam structure, in which case units added to the face of the existing dam cost $\$ 2,470 / \mathrm{kW}$. This dam scenario is referred to below as "No Provision Made for Additional Hydro Units at the Time of Dam Construction."

Dam Scenario II Provision was made to add penstocks and generators to the existing dam structure, in which case the cost is only $\$ 700 / \mathrm{kW}$. This condition is not all that unusual. The Akosombo complex was completed in 1965 with 4 hydro units installed and with two extra bays for future generation additions [21]. These were installed in 1972. The Revelstoke dam complex in Canada is now considering installing generators in the two empty bays built into the complex at the time of construction [2], as is the Libby dam complex in Montana [25]. Other examples certainly exist 
where hydro complexes are built anticipating increases in future peak system demands. These structures are built into the original dam because it is much cheaper to build them at that time than to modify the dam structure later. This dam scenario is referred to below as "Inexpensive Retrofit Options Present."

\subsection{Presence of external markets for firm and non-firm electricity, and capacity}

Market Scenario I All markets are present. This market scenario is referred to below as "External Markets Present."

Market Scenario II No markets are present. This market scenario is referred to below as "No External Markets Present."

With two alternative scenarios for dam retrofitting and two for markets, we arrive at four cases.

\section{Case I: External markets and inexpensive retrofit options present}

(A) Least cost solution Least cost solutions to capacity expansion problems of the type considered in this paper involve trade-offs between the two competing requirements of any electric system: (1) that it meet projected energy (MWh) demands of the system and (2) that it meet projected capacity (MW) reserve requirements. Least cost solutions to meet the first goal are achieved by building generation options that minimize the annualized operating and capital cost of generation, such as Combined Cycle units for base load or Combustion Turbines for peak load, or purchasing firm or non-firm capacity. The second goal is achieved by choosing generation options that minimize only the annualized capital cost, such as Combustion Turbines, or purchasing capacity or firm energy, if such markets exist. The economic trade-offs between these two competing constraints depend chiefly on the "lumpiness" and capital cost of the high efficiency (40 percent) Combined Cycle units, which are large multi-hundred MW units with capital costs in the neighborhood of $\$ 800 / \mathrm{kW}$, and the smaller 50 to $100 \mathrm{MW}$ less efficient (30 percent) Combustion Turbines, with capital costs in the neighborhood of $\$ 500 / \mathrm{kW}$. The impact of lumpiness on the decision is mitigated by the presence of external markets for firm and non-firm power and capacity, which can be purchased in any quantity. However, purchases cost more per $\mathrm{kW}$ or $\mathrm{kWh}$ than a fully utilized build option, since merchant plant enterprises are inherently more risky than captive plants, resulting in higher capital recovery factors (CRFs), and mark-up add-ons to reflect transaction costs. (The model uses a CRF of 12 percent for construction, while purchase costs are based on a 15 percent CRF.) Least cost strategies tend to be a mix of make and buy electricity, either (a) satisfying the energy constraint by building Combined Cycle units and satisfying the reserve margin constraints by purchasing capacity in the open market, or (b) satisfying the reserve margin constraints by building Combustion Turbines and purchasing energy in the open market.

When external options for purchasing capacity alone, energy alone (non-firm power), or both (firm power) are added to systems which have reservoirs and hydroelectric power options (basically storable electricity) the optimization problem 
becomes very complex. This is particularly true when decisions regarding the type of capacity to add need to be made in a system where peak (MW) and energy (MWh) demands are growing at uncertain rates. In the situation considered in this paper, potential capacity shortfalls range from 10 percent to 30 percent of current capacity, with energy shortfalls having an even wider range because of weather related uncertainty regarding water availability for hydropower generation. Fortunately, stochastic programming is a tool designed for application to just such problems, allowing the optimization to trade off and evaluate the needs of low probability scenarios (e.g. droughts, floods, extremely high or low demand growth) against less severe higher probability scenarios (normal weather, normal growth).

Table 2 summarizes selected numerical results for all the runs. The objective function value for least cost operation in Case IA in Table 2, is \$366 million dollars or about 2.7 cents $/ \mathrm{kWh}$. (The low cost $/ \mathrm{kWh}$ is because no cost recovery for existing equipment is in the model-only operating costs, and the costs of new equipment.) This is achieved in the following way.

(1) The model builds two $330 \mathrm{MW}$ combined cycle (CC) plants, buys fuel for them and the existing $\mathrm{CC}$ unit in the forward gas markets, and operates the $\mathrm{CC}$ units at capacity as base load plants in both the wet and dry seasons.

(2) The model builds one additional $110 \mathrm{MW}$ simple cycle (SC) plant, and operates both the new and old SC plants as peaking plants, operating only in the high demand and/or drought scenarios and buying gas for them on the spot markets in these scenarios.

(3) The model builds no additional hydro capacity, and operates the dam complex at reduced levels during the wet season in order to store water for use during the dry season. The Akosombo and Kpong generating units operate in near lock step, since in this scenario, the Kpong units convert nearly all the water discharged through the Akosombo turbines to electricity, spilling only a small amount, mostly in the wet season. These spillage amounts are not enough to warrant building additional generating capacity at the Kpong dam site. Wet season inflows stored in the Akosombo reservoir for use during the dry season vary depending on the wet season scenario, ranging from over 50 percent in the flood scenario to 35 percent in the dry scenario. This stored water allows the Akosombo complex to generate substantial amounts of electricity in the dry season.

(4) Regarding purchases and sales of electricity to and from the grid, the model trades in only two of the three commodities, buying and selling capacity and purchasing non-firm power. Rather than build a second SC plant, the model purchases capacity in high demand scenarios to meet reserve requirements, and sells excess capacity in low demand scenarios. In the wet season high demand and dryer than normal scenarios, the model meets about 20 percent of demand with non-firm power, and purchases somewhat less during the dry season.

(B) ROR operation solution Case IB of Table 2 shows the objective value for this case to be $\$ 396$ million, an ROR operation cost penalty of $7.6 \%$ over least cost operation for this scenario.

With ROR operation forcing the ending wet season water inventory to equal the beginning wet season inventory, rather than store some for use in the dry season, the 
Table 2 Scenario results with and without Run of River (ROR) operations

\begin{tabular}{|c|c|c|c|c|c|c|c|c|}
\hline & $\begin{array}{l}\text { Case } \\
\text { IA }^{\mathrm{a}}\end{array}$ & $\begin{array}{l}\text { Case } \\
\text { IB }\end{array}$ & $\begin{array}{l}\text { Case } \\
\text { IIA }\end{array}$ & $\begin{array}{l}\text { Case } \\
\text { IIB }\end{array}$ & $\begin{array}{l}\text { Case } \\
\text { IIIA }\end{array}$ & $\begin{array}{l}\text { Case } \\
\text { IIIB }\end{array}$ & $\begin{array}{l}\text { Case } \\
\text { IVA }\end{array}$ & $\begin{array}{l}\text { Case } \\
\text { IVB }\end{array}$ \\
\hline Cost (\$ Mil.) & 366 & 396 & 366 & 434 & 408 & 700 & 408 & 700 \\
\hline \multicolumn{9}{|l|}{ Construction (MW) } \\
\hline Combined Cycle & 660 & 660 & 660 & 660 & 990 & 1320 & 990 & 1320 \\
\hline Combustion Turbine & 110 & 0 & 110 & 110 & 110 & 0 & 110 & 0 \\
\hline Hydro & 0 & 680 & 0 & 0 & 0 & 0 & 0 & 0 \\
\hline Transmission & 0 & 400 & 0 & 400 & 0 & 0 & 0 & 0 \\
\hline \multicolumn{9}{|l|}{ Expected Trade ${ }^{b}$} \\
\hline $\begin{array}{l}\text { Capacity Purchases in Hi D } \\
\text { (MW) }\end{array}$ & 60 & 0 & 60 & 60 & 0 & 0 & 0 & 0 \\
\hline Capacity Sales in Lo D (MW) & 70 & 550 & 70 & 70 & 0 & 0 & 0 & 0 \\
\hline $\begin{array}{l}\text { Non-firm Purchases in Wet } \\
\text { (GWh) }\end{array}$ & 1,005 & 145 & 1,005 & 158 & 0 & 0 & 0 & 0 \\
\hline Non-firm Sales in Dry (GWh) & 0 & 0 & 0 & 0 & 0 & 0 & 0 & 0 \\
\hline $\begin{array}{l}\text { Non-firm Purchases in Dry } \\
\text { (GWh) }\end{array}$ & 560 & 2298 & 560 & 2,166 & 0 & 0 & 0 & 0 \\
\hline \multicolumn{9}{|l|}{ Hydro } \\
\hline $\begin{array}{l}\text { Expected Generation in Wet } \\
(\mathrm{GWh})\end{array}$ & 2,805 & 4,289 & 2,805 & 4,661 & 2,207 & 4,661 & 2,207 & 4,661 \\
\hline $\begin{array}{l}\text { Expected Generation in Dry } \\
(\mathrm{GWh})\end{array}$ & 2,460 & 497 & 2,460 & 568 & 2,759 & 568 & 2,759 & 568 \\
\hline $\begin{array}{l}\text { Expected Akosombo Spill in } \\
\text { Wet }\left(10^{9} \mathrm{ft}^{3}\right)\end{array}$ & 0 & 0 & 0 & 189 & 0 & 189 & 0 & 189 \\
\hline $\begin{array}{l}\text { Expected Akosombo Spill in } \\
\text { Dry }\left(10^{9} \mathrm{ft}^{3}\right)\end{array}$ & 0 & 0 & 0 & 0 & 0 & 0 & 0 & 0 \\
\hline $\begin{array}{l}\text { Expected Kpong Spill in Wet } \\
\left(10^{9} \mathrm{ft}^{3}\right)\end{array}$ & 44 & 280 & 44 & 275 & 228 & 275 & 228 & 275 \\
\hline $\begin{array}{l}\text { Expected Kpong Spill in Dry } \\
\left(10^{9} \mathrm{ft}^{3}\right)\end{array}$ & 12 & 0 & 12 & 0 & 33 & 0 & 33 & 0 \\
\hline \multicolumn{9}{|l|}{ Thermal Generation } \\
\hline $\begin{array}{l}\text { Expected Combined Cycle in } \\
\text { Wet (GWh) }\end{array}$ & 3,526 & 2,662 & 3,526 & 2,874 & 4,680 & 3,037 & 4,680 & 3,037 \\
\hline $\begin{array}{l}\text { Expected Combined Cycle in } \\
\text { Dry (GWh) }\end{array}$ & 3,234 & 3,541 & 3,234 & 3,541 & 3,494 & 5,137 & 3,494 & 5,137 \\
\hline $\begin{array}{l}\text { Expected Combustion Turbine } \\
\text { in Wet (GWh) }\end{array}$ & 51 & 0 & 51 & 0 & 116 & 0 & 116 & 0 \\
\hline $\begin{array}{l}\text { Expected Combustion Turbine } \\
\text { in Dry (GWh) }\end{array}$ & 58 & 41 & 58 & 38 & 56 & 0 & 56 & 0 \\
\hline Stopgap Measures & & & & & & & & \\
\hline
\end{tabular}


Table 2 (Continued)

\begin{tabular}{lcrrrrrrr}
\hline & $\begin{array}{l}\text { Case } \\
\text { IA }^{\mathrm{a}}\end{array}$ & $\begin{array}{l}\text { Case } \\
\text { IB }\end{array}$ & $\begin{array}{l}\text { Case } \\
\text { IIA }\end{array}$ & $\begin{array}{l}\text { Case } \\
\text { IIB }\end{array}$ & $\begin{array}{l}\text { Case } \\
\text { IIIA }\end{array}$ & $\begin{array}{l}\text { Case } \\
\text { IIIB }\end{array}$ & $\begin{array}{l}\text { Case } \\
\text { IVA }\end{array}$ & $\begin{array}{l}\text { Case } \\
\text { IVB }\end{array}$ \\
\hline $\begin{array}{l}\text { Distributed Generation in Wet } \\
\text { (GWh) }\end{array}$ & 0 & 0 & 0 & 0 & 94 & 0 & 94 & 0 \\
$\begin{array}{l}\text { Distributed Generation in Dry } \\
\text { (GWh) }\end{array}$ & 0 & 5 & 0 & 0 & 52 & 387 & 52 & 387 \\
$\begin{array}{l}\text { Unmet Demand in Dry } \\
(\mathrm{GWh}) \mathrm{c}\end{array}$ & 0 & 0 & 0 & 0 & 69 & 201 & 69 & 201 \\
\hline
\end{tabular}

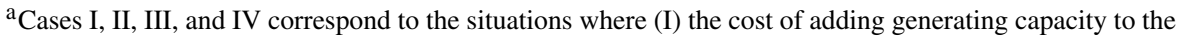
dam is low and markets for generating capacity, firm and non-firm electricity are all present; (II) the cost of adding dam capacity is high and the various electricity markets are available; (III) the cost of adding dam capacity is low and the various electricity markets are not available; (IV) the cost of adding dam capacity is high and the various electricity markets are not available. In all cases, the objective is to minimize the investment and operating costs of satisfying electricity demand. The case designation of A or B indicates (A) that run of river (ROR) constraints are not imposed and (B) ROR constraints are imposed

${ }^{\mathrm{b}}$ There is no trade in firm electricity or non-firm sales in any case

${ }^{\mathrm{c}}$ There is no unmet demand in the wet season in any case

model chooses to purchase $680 \mathrm{MW}$ of additional hydro capacity to allow it to use all water to generate electricity even in the maximum wet season flood scenarios, which would otherwise have to be spilled. The model also builds an additional transmission line to handle increased exports associated with ROR operation, and as in Case IA, builds two CC plants to satisfy demand.

Trade patterns in the ROR case differ substantially from the cost minimization case. In the wet season, the model adjusts to the $680 \mathrm{MW}$ of additional hydro generation capacity installed to allow outflows from the dam to equal inflows in the wet season by: (a) substituting the hydro capacity for the combustion turbine capacity and capacity purchases to cover the capacity requirements in the high demand scenarios; (b) selling almost all this capacity in the low demand scenarios; (c) nearly eliminating non-firm purchases permitted by the doubling of hydro output; (d) increasing hydro generation by $50 \%$ in the wet season.

In the dry season with reduced hydro generation capability due to lack of water stored for generation use, the model: (a) dramatically increases the amount of dry season non-firm purchases and (b) dramatically decreases the amount of hydro generation. There is some increased wet season spillage from the Kpong dam downstream from the major Akosombo complex in both the flood and wet scenarios, but again this is not enough to justify adding capacity to the Kpong complex.

In short, the model takes advantage of the increased hydro generation capability forced by having to follow ROR rules by using the capacity to substitute for imported capacity in the high demand scenarios, selling that capacity in the low demand scenarios, and by substituting imported power for the reduced hydro capability in the dry season, thus minimizing the economic impact of the ROR no storage requirement. 
Case II: External markets present with no provision made for additional hydro units at the time of dam construction

(A) The least cost solution The solution to this case is identical to the base case\$366 million-because the least cost solution to neither Case I nor Case II involves the construction of additional hydro generating capacity.

(B) ROR solution Under these circumstances, the ROR operating cost is considerably higher-\$434 million-or 18 percent more than the $\$ 366$ million cost when operating to minimize the operating and capital costs of the system.

With regard to the ROR solution, the much higher $(\$ 2,400$ vs. $\$ 700 / \mathrm{kW}$ ) costs of additional hydro sends the model in the direction of a completely different method of satisfying the flow constraints of ROR operation than is found when the hydro costs are lower. Rather than build additional hydro capacity to allow outflows to equal inflows, the model fills the reservoir to capacity at the beginning of the representative year, allowing the high inflows to escape over the Akosombo spillway, spilling almost half of the inflows in the flood scenario_a "fill and spill" strategy. The annualized filling process is costly (over $\$ 70$ million) in that it diverts water to fill the reservoir that would otherwise be used to generate electricity, as is the wasted electricity value of the spillage itself. Nonetheless, it is a cheaper alternative than constructing very expensive hydro generators and utilizing the water to generate, particularly with the improvement in water turbine productivity $\left(\mathrm{ft}^{3} / \mathrm{MWh}\right)$ caused by the increased head associated with the filled reservoir. What is somewhat surprising is that the model does not choose to install hydro generators on the spillway, an available option. The choice makes sense when it is recognized that unlike generators installed in the face of the dam which can have value in all scenarios, these generators will have water to operate only during the flood and wet scenarios in the wet season when the spillway is in use.

As Table 2 indicates, in Case IIB: (a) in the wet season water is spilled from both the Akosombo and Kpong complexes to assure outflows equal inflows; (b) compared to Case IIA, there is a substantial increase in hydro generation in the wet season; (c) a corresponding decrease in the dry season; and (d) the model substantially decreases wet season non-firm purchases in all scenarios, and increases them in all dry season scenarios. Thus, non-firm purchases substitute for stored water, shifting purchases from wet to dry seasons as hydro generation shifts resources from dry to wet to meet the ROR operating requirements.

The ROR penalty in this situation can be much less, if provision was made for release of flood waters through a flood tunnel in the face of the dam that allows water to be released without having to fill the dam to capacity and using the spillway as a release mechanism. In this case, the ROR cost penalty drops to within 4 percent of that in Case I above.

\section{Case III: No markets are present, but inexpensive hydro retrofit options present}

(A) Least cost solution In this case, the minimum cost without ROR operation is $\$ 408$ million, an increase of 11.5 percent over the costs when markets are present. The 
least cost solution with trade allowed (Case I above) met between 15 and 20 percent of demand with non-firm market purchases, depending on the scenario, and satisfied 10 to 15 percent of the reserve margin with purchases in high demand scenarios and sold a similar percent during low demand scenarios.

Without these trade options, the model is forced to build three combined cycle units for base load, and one CT to help meet the capacity and energy requirement deficiencies caused by the trade restriction. The $990 \mathrm{MW}$ of new CC capacity is utilized to meet over two thirds of demand in the wet season and a slightly smaller fraction in the dry season. Akosombo hydro generation is used extensively in the flood and wet scenarios in the wet season, and to a much lesser extent in the drought scenarios of the wet season. Storage of wet season water for dry season use allows hydro generation to be roughly equal in the wet and dry seasons. Substantial Kpong spillage takes place in both the wet and dry season flood scenarios.

As mentioned, there is some use of distributed generation in the drought and high demand scenarios in both the wet and dry seasons. A maximum of 753 thousand MWh of distributed generation is used in these high demand scenarios, which is the assumed capacity of distributed generation units in the model. This represents about 10 percent of demand in these cases. The shift to this expensive option is required because capacity limitations of the gas supply system prevent the CC and CT units from generating more electricity.

(B) ROR solution The cost of the ROR strategy in this scenario is $\$ 700$ million, a 71 percent increase over the least cost strategy in this scenario. The ROR strategy for meeting the ROR flow requirements in the absence of markets is to adopt the "fill and spill" strategy employed in case IIB above, spilling water from both the Akosombo and Kpong complexes in the wet season. This "wasted" water spillage also requires the construction of $4 \mathrm{CC}$ units to meet dry season demand. In addition, since the capacity of the gas delivery system to the thermal units is limited, the model is forced to call upon all of the distributed generation capacity available to meet demand in the dry season. But even this is insufficient, and the model is forced to leave 10 percent of demand unserved in 3 rare, but nonetheless possible drought scenarios. (One can imagine this resulting in a public relations nightmare for hydro system managers having to explain to the public why they chose to spill water in the wet season and then were forced to ration electricity in the following dry season.)

The $\$ 700$ million cost is just below the cost of the alternative of building four relatively inexpensive $(\$ 700 / \mathrm{kW})$ Akosombo hydro units to meet ROR flow requirements, and build 4 combined cycle plants to meet dry season demands.

The competitiveness of these two alternative strategies emphasizes the importance of correctly estimating the relationship between water turbine productivity and the volume of water in the reservoir, which in turn depends on the contours of the specific reservoir examined. A very minor change in the productivity value used when the reservoir is full will make the 4 hydro unit construction option cheaper than the fill and spill option. 
Case IV: No markets present, and no provision for inexpensive hydro units made at the time of construction

Both the least cost and ROR solutions are identical to those in Case III above. What is different in this case is that the cost of the alternative ROR strategy of building 4 hydro units rather than filling the reservoir increases dramatically, since the hydro units cost $\$ 2,400 / \mathrm{kW}$, not $\$ 700 / \mathrm{kW}$. However, because that option was not selected in Case III, it will surely not be selected in Case IV.

The impact of the presence of specific markets on the ROR penalty Which of the external markets is most crucial in producing these results? In Case Ib above, the situation where low cost hydro units are available with only non-firm markets present, the cost rises from $\$ 396$ to 417 million, increasing the ROR cost penalty to 14 percent. When only firm power contracts are available, the ROR penalty increases to 31 percent of the least cost solution, and when only capacity markets are present the penalty grows to 83 percent of the least cost solution. When markets for both firm and non-firm power exist, ROR costs are $\$ 415$ million, an ROR penalty of 13 percent. Thus, the combination of all three markets taken together reduces the penalty more than the sum of the penalty reductions for each one separately.

Relaxing the ROR constraint A series of experiments for Case I were carried out allowing the progressive relaxation of the ROR constraint by allowing a varying percentage of wet season ending water inventory to be stored for use in the dry season. The results showed that if 1 percent of the opening inventory was allowed to be stored for such use, the ROR penalty decreased from $\$ 30$ million to $\$ 28$ million, or 7.6 percent of the minimum cost value. On the other hand, a 5 percent allowance resulted in the ROR penalty dropping to $\$ 23$ million, a 4.6 percent ROR penalty. Clearly, the gains from relaxing the ROR constraint are highly nonlinear with much larger gains per unit of relaxation for small shifts than for large shifts.

A substantial decrease in the Case I ROR penalty resulted when the ROR constraint was imposed only during flood conditions. In this case, the dam management is free to optimize water use except when flood events occur, at which time they must follow the ROR pattern of matching inflows to outflows. If this rule is followed, the ROR penalty decreases to $\$ 19$ million, or only 4 percent of least cost operation. The magnitude of the reduction makes this an attractive option for ROR advocates, since outflows only equal inflows during periods when the reservoir and surrounding land is saturated with rain and inflows.

\section{Market potential for low cost ROR operation}

There are studies that estimate the undeveloped hydro potential for three categories of sites in the U.S.: existing reservoirs with power installed now, reservoirs with no power, and undeveloped sites. In 1998, the Idaho National Engineering and Environmental Laboratory published a survey [3] which indicated that over 7,800 MW of hydropower capacity at sites with power installed now could be developed. After 
applying a series of environmental suitability factors to these totals in the form of probabilities of development, the expected value of the total was reduced to 4,300 MW. The total for reservoirs with no power was 29,625 MW before environmental suitability adjustments and 17,000 MW after the adjustments were made. Since U.S. markets for all three types of power (firm power, non-firm power, and capacity) exist, a reasonable estimate of the market potential for low cost ROR operation in the United States is somewhere around 20,000 MW. What fraction of this total would be economic remains undetermined, since economic feasibility was not part of our screening process.

\section{Summary of results}

The specific estimates of the incremental costs are obviously dependent on the data used to populate the model. Nonetheless, after a series of experiments with varying data sets, the following general conclusions seem to be robust.

I. If provision was made for the installation of additional hydro units to the dam face at the time of construction and markets for the purchase and sale of firm and nonfirm power and capacity exist, then the ROR operating penalty can be modest, about 8 percent of total operating and new equipment costs for the representative data in the model.

II. If provision was not made for installation of additional hydro units, and all markets are present, but the dam can be operated at near the reservoir capacity, allowing water to be spilled to meet ROR flow requirements, then the ROR penalty is on the order of 18 percent, and well less than half of that if spillage can take place through flood tunnels, rather than over the spillway.

III. If markets for firm and non-firm power and capacity are not present, then the ROR cost penalty is prohibitive, near 70 percent, regardless of whether there is a low-cost means of adding hydro generation units to the dam. Further, without such markets, there are several weather scenarios where the utility must explain to its customers why it chose to spill water in the wet season, only to have to curtail service in the dry for lack of generation capability.

IV. In Case I above, relaxing the ROR constraint by requiring the ROR constraint to only hold in the flood scenario (thus achieving the periodic flushing goals of ROR) has a substantial impact on the ROR penalty, reducing it to only 4 percent. Relaxing the ROR constraint by allowing 1 percent of the opening inventory to be stored and used in the wet season reduces the penalty in case I above to about 7 percent, while allowing 5 percent to be stored decreases the penalty to 4.5 percent.

V. The ROR penalty increases to 14 percent in Case I if only markets for non-firm electricity exist (i.e. there are no markets for firm electricity or capacity). If only markets for firm electricity or capacity exist, the ROR penalty increases substantially (31 percent and 83 percent, respectively). This is because without non-firm markets to allow purchases or sales in response to weather, markets for firm electricity or capacity committed to before the weather scenarios are known are of minor value in reducing the ROR penalty. 
These results are based on the use of 3 separate internally consistent data sets developed from different sources. Thus, the conclusions reached should not be taken as recommendations for any specific site, specifically the Ghana Akosombo dam complex. Rather the objective of this paper is to establish a framework for identifying conditions that are favorable for ROR operation. Our hope is that these conditions can be developed into a screening tool for identifying hydro-thermal complexes that may be most conducive to adapting to ROR operation at modest cost.

\section{Conclusions}

There are several general conclusions that can be drawn from this paper. The main point is that given the proliferation of traded electricity commodities (firm power, non-firm power, capacity, etc.) in recent years, the existence of these multiple markets creates, in certain circumstances, an opportunity to operate dam complexes in an ROR mode without great economic penalty. Of course, these incremental costs must be balanced with the environmental benefits of ROR operation to achieve a net gain, and situations where the benefits are large relative to substantial incremental ROR costs could still be worth pursuing.

More generally, this paper, and papers like it which look to mitigate the economic impact of environmentally friendly paths of action, serve as an alternative to the approach by many constituencies of simply stonewalling such actions. Those following this approach usually start by denying the problem exists or by admitting it exists, but insisting that the cost of such actions are too expensive to even consider.

An example of the first approach would be those who still deny the existence of man made global warming. Those who adopt the "too costly to consider" strategy include many in the hydroelectricity community regarding the problem we address in this paper, and, more famously, the initial response of the utility industry to acid rain legislation in the 80's, whose cost analysis of the legislation seemed by many to be based on finding the maximum cost of compliance, rather than the minimum cost.

Finally, As was stated in the introduction, the practical usefulness of this paper lies in identifying situations where altering the operating rules of existing dams to allow reservoir outflow patterns to better match reservoir inflows-so called ROR operation of the reservoirs-will likely result in acceptable increases in the cost of electricity generation, and where such increases will be prohibitive. The market potential for projects where the ROR cost penalty may be reasonable appears to be sufficiently large to warrant further investigation of those sites where the conditions are most favorable.

Open Access This article is distributed under the terms of the Creative Commons Attribution Noncommercial License which permits any noncommercial use, distribution, and reproduction in any medium, provided the original author(s) and source are credited.

\section{Appendix: Mathematical formulation of stochastic planning model}

The following notation is used in the mathematical statement of the model constraints and objective. The model documented below is for the minimum cost prob- 
lem. Changes needed to implement run of river are indicated at the end of the model documentation.

\section{Index sets}

$h$

$w$

$d$

Scalar constants

WLevNow
ResMar
Ft3perMWHROR

Ft3perMWHHiH

Ft3perMWHK

BtuperMWHSC

BtuperMWHCC

CapSCE

CapSCN

CapPipe

CapCCE

CapCCN

CostCapSCN

CostCapCCN

HoursW

HoursD

CapDist

CapAE

CapAN

CostCapAN

CAPROR

COSTCAPROR

$\mathrm{CAPHiH}$

COSTCAPHiH

CapKE

CapKN

CostCapKN

CapTrE

CapTrN
States for demand growth and forward price

States for wet season

States for dry season

Current water level (billion $\mathrm{ft}^{3}$ )

Reserve margin

Water per unit of electricity for ROR (billion $\mathrm{ft}^{3}$ per thousand $\mathrm{MWh}$ )

Water per unit of electricity for High Head (billion $\mathrm{ft}^{3}$ per thousand MWh)

Water per unit of electricity of Kpong (billion $\mathrm{ft}^{3}$ per thousand MWh)

Gas per unit of electricity for simple cycle (trillion Btu per thousand MWh)

Gas per unit of electricity for combined cycle (trillion Btu per thousand MWh)

Capacity of existing simple cycle unit (thousand MW)

Capacity of new simple cycle unit (thousand MW)

Capacity of Gas Pipeline (trillion Btu)

Capacity of existing combined cycle unit (thousand MW)

Capacity of new combined cycle unit (thousand MW)

Cost of capacity of new simple cycle unit (million USD)

Cost of capacity of new combined cycle unit (million USD)

Number of hours in wet season (hours)

Number of hours in dry season (hours)

Capacity of distributed generation (thousand MW)

Capacity of existing Akosambo generating units (thousand MW)

Capacity of new Akosambo generating unit (thousand MW)

Cost of capacity of new Akosambo generating unit (million USD)

Capacity of new ROR unit (thousand MW)

Cost of capacity of new ROR unit (million USD)

Capacity of new High head unit (thousand MW)

Cost of new High head unit (million USD)

Capacity of existing Kong generating units (thousand MW)

Capacity of new Kong generating units (thousand MW)

Cost of capacity of new Kong generating unit (million USD)

Capacity of existing transmission lines (thousand MW)

Capacity of new transmission lines per unit (thousand MW) 


\section{CostCapTrN}

CostFill

StorCap

PUMD

PenstockWL

CRF

Indexed constants

PeakDW $W_{h}$

CostCAPPW $W_{h}$

PEpurWF $_{h}$

InFlowAW $W_{w}$

$\operatorname{Prh}_{h}$

PFGas $W_{h}$

PEsalWF $_{h}$

$\operatorname{RevCAPSW}_{h}$

PeakDD $D_{h, w}$

PGPurW $_{h, w}$

$\mathrm{PGSalW}_{h, w}$

PDist $_{h, w}$

PEPurWNF $_{h, w}$

PESalWNF $_{h, w}$

PEPurDF $_{h, w}$

InFlow $A D_{w, d}$

PFGasD ${ }_{h, w}$

PESalDF $_{h, w}$
Cost of capacity of new transmission lines per unit (million USD)

Cost to fill reservoir (million USD per billion $\mathrm{ft}^{3}$ )

Dam capacity (billion $\mathrm{ft}^{3}$ )

Cost of unmet demand (million USD per thousand MWh)

Minimum level of the dam (billion $\mathrm{ft}^{3}$ )

Capital recovery factor

Wet season peak demand in demand-price state $h$ (thousand MW)

Cost of capacity purchased at beginning of wet season state $h$ (million USD per thousand MW)

Price of firm power purchase at beginning of wet season state $h$ (million USD per thousand MWh)

Water inflows into Akosambo during the wet season state $w$ (trillion $\mathrm{ft}^{3}$ )

Probability of demand growth and forward price state $h$

Price of forward gas in state $h$ at beginning of wet (million USD per trillion Btu)

Revenue from sale of firm power in state $h$ at beginning of wet season (million USD per thousand MWh)

Revenue from sale of capacity in state $h$ at beginning of wet season (million USD per thousand MW)

Peak dry season demand in state $h$ followed by state $w$ (thousand MW)

Purchase price of spot gas in state $h$ followed by state $w$ during wet season (million USD per trillion Btu)

Sale price of spot gas in state $h$ followed by state $w$ during wet season (million USD per trillion Btu)

Cost of distributed generation in state $h$ followed by state $w$ during wet season (million USD per thousand MWh)

Purchase price of spot electricity in state $h$ followed by state $w$ during wet (million USD per thousand MWh)

Sale price of spot electricity in state $h$ followed by state $w$ during wet season (million USD per thousand MWh)

Purchase price of firm electricity in state $h$ followed by state $w$ at beginning of dry season (million USD per thousand $\mathrm{MWh}$ )

Water inflows into Akosambo in state $w$ followed by state $d$ during the dry season (billion $\mathrm{ft}^{3}$ )

Price of forward gas in state $h$ followed by state $w$ at the beginning of the dry season (million USD per trillion Btu)

Sale price of firm electricity in state $h$ followed by state $w$ at beginning of the dry season (million USD per thousand $\mathrm{MWh}$ ) 
PGPurD ${ }_{h, w, d}$

$P_{\text {SalD }}, w, d$

PDistD $h, w, d$

PEPurDNF $_{h, w, d}$

PESalDNF $_{h, w, d}$

$\operatorname{Dem} W_{h, w}$

$\operatorname{DemD}_{h, w, d}$

$\operatorname{Prwd}_{w, d}$
Purchase price of spot gas in state $h$ followed by state $w$ followed by state $d$ during the dry season (million USD per thousand MWh)

Sale price of spot gas in state $h$ followed by state $w$ followed by state $d$ during the dry season (million USD per trillion Btu) Cost of distributed demand at during dry (million USD per thousand MWh)

Purchase price of spot electricity in state $h$ followed by state $w$ followed by state $d$ during the dry season (million USD per thousand MWh)

Sale price of spot electricity in state $h$ followed by state $w$ followed by state $d$ during dry (million USD per thousand MWh)

Electricity demand in state $h$ followed by state $w$ during the wet season (thousand MWh)

Electricity demand in state $h$ followed by state $w$ followed by state $d$ during the dry season (thousand MWh)

Joint probability of weather state $d$ in the dry season given that weather state $w$ occurred in the wet season

Non-negative variables

Ft3perMWHA

WLev

$C A P P W_{h}$

CAPSW $W_{h}$

$\mathrm{EPurWF}_{h}$

EsalWF $_{h}$

$\mathrm{FGas}_{h}$

TGenWSC $C_{h, w}$

TGenWCC $C_{h, w}$

$H G e n W_{h, w}$

HGenWROR $\mathrm{W}_{h, w}$

$\mathrm{HGenWHiH}_{h, w}$
Water per unit of electricity of Akosambo (billion $\mathrm{ft}^{3}$ per thousand MWh)

Water inventory at beginning of the representative year (billion $\mathrm{ft}^{3}$ )

Purchase of capacity from the grid market in state $h$ prior to the beginning of the wet season (thousand MW)

Sale of capacity to the grid market in state $h$ prior to beginning of the wet season (thousand MW)

Purchase of firm electricity in state $h$ prior to beginning of the wet season (thousand MWh)

Sale of firm electricity in state $h$ prior to beginning of the wet season (thousand MWh)

Forward gas purchases in state $h$ prior to beginning of the wet season (trillion Btu)

Simple cycle thermal generation in state $w$ following state $h$ during the wet season (thousand MWh)

Combined cycle thermal generation in state $w$ following state $h$ during the wet season (thousand MWh)

Hydro generation on Akosambo in state $w$ following state $h$ during the wet season (thousand $\mathrm{MWh}$ )

Hydro generation from ROR in state $w$ following state $h$ during wet season (thousand MWh)

Hydro generation from High head in state $w$ following state $h$ during wet season (thousand MWh) 
$H G e n W_{h, w}$

GPurW $_{h, w}$

$G_{S a l} W_{h, w}$

$\operatorname{EPurWNF}_{h, w}$

$E_{S a l W N F}, w$

SpilWA $_{h, w}$

$\operatorname{SpilWK}_{h, w}$

Water $_{h, w}$

$\operatorname{Dist}_{h, w}$

$U n M D W_{h, w}$

$F G a s D_{h, w}$

EPurDF $_{h, w}$

$\operatorname{EsalDF}_{h, w}$

TGenDSC $C_{h, w, d}$

TGenDCC $C_{h, w, d}$

$H_{G e n D A}, w, d$

$H_{G e n D R O R}, w, d$

$\mathrm{HGenDHiH}_{h, w, d}$

$H_{G e n D K}, w, d$

$\operatorname{GPurD}_{h, w, d}$

GSalD $_{h, w, d}$

EPurDNF $_{h, w, d}$

ESalDNF $_{h, w, d}$
Hydro generation on Kpong in state $w$ following state $h$ during wet season (thousand MWh)

Gas spot purchase in state $w$ following state $h$ during the wet season (trillion Btu)

Gas spot sales in state $w$ following state $h$ during the wet season (trillion Btu)

Electricity non-firm purchase in state $w$ following state $h$ during wet season (thousand MWh)

Electricity non-firm sales in state $w$ following state $h$ during the wet season (thousand MWh)

Spillage in state $w$ following state $h$ during the wet season from Akosambo (billion $\mathrm{ft}^{3}$ )

Spillage in state $w$ following state $h$ during the wet season from Kpong (billion $\mathrm{ft}^{3}$ )

Water inventory at end of wet season in state $w$ following state $h$ (billion $\mathrm{ft}^{3}$ )

Distributed generation in state $w$ following state $h$ during wet season (thousand MWh)

Unmet demand in state $w$ following state $h$ during wet season (thousand MWh)

Forward gas purchases in state $w$ following state $h$ at beginning of the dry season (trillion Btu)

Firm purchases of electricity in state $w$ following state $h$ at beginning of the dry season (thousand MWh)

Firm sale of electricity in state $w$ following state $h$ at beginning of the dry season dry season (thousand MWh)

Simple cycle thermal generation in state $d$ following state $w$ following state $h$ during dry season (thousand MWh)

Combined cycle thermal generation in state $d$ following state $w$ following state $h$ during the dry season (thousand MWh)

Hydro generation on Akosambo in state $d$ following state $w$ following state $h$ during the dry season (thousand MWh)

Hydro generation from ROR in state $d$ following state $w$ following state $h$ during the dry season (thousand $\mathrm{MWh}$ )

Hydro generation from high head in state $d$ following state $w$ following state $h$ during the dry season (thousand MWh)

Hydro generation on Kpong in state $d$ following state $w$ following state $h$ during the dry season (thousand MWh)

Gas spot purchase in state $d$ following state $w$ following state $h$ during the dry season (trillion Btu)

Gas spot sales in state $d$ following state $w$ following state $h$ during the dry season (trillion Btu)

Electricity non-firm purchase in state $d$ following state $w$ following state $h$ during the dry season (thousand MWh)

Electricity non-firm sales in state $d$ following state $w$ following state $h$ during the dry season (thousand MWh) 
$\operatorname{SpilDA}_{h, w, d}$

$\operatorname{SpilDK}_{h, w, d}$

Water $_{h, w, d}$

Dist $D_{h, w, d}$

$U n M D D_{h, w, d}$
Spillage in state $d$ following state $w$ following state $h$ during the dry season from Akosambo (billion $\mathrm{ft}^{3}$ )

Spillage in state $d$ following state $w$ following state $h$ during the dry season from Kpong (billion $\mathrm{ft}^{3}$ )

Water inventory in state $d$ following state $w$ following state $h$ at end of the dry season (billion $\mathrm{ft}^{3}$ )

Distributed generation in state $d$ following state $w$ following state $h$ during the dry season (thousand $\mathrm{MWh}$ )

Unmet demand in state $d$ following state $w$ following state $h$ during the dry season (thousand MWh)

Unrestricted variable

ECost

Expected cost (million USD)

Integer variables

HExpHiH

HExpA

HExpK

TExp

TSCExp

TrExp

HexpROR
Hydro expansions for Akosombo high head (units)

Hydro expansions for Akosambo Conventional (units)

Hydro expansions for Kpong (units)

Thermal expansions - combined cycle (units)

Thermal expansions-simple cycle (units)

Transmission expansions (units)

Hydro expansions for Akosombo ROR (units)

Constraints

Floodgate

Limit on floodgates (number of potential expansions)

$H \operatorname{expROR}+\mathrm{HexpHiH} \leq 12$

Wet season constraints (conditional on state $h$ )

PeakDbalW

Capacity balance for the wet season in state $h$ (thousand MW)

PeakDW $W_{h} *$ ResMar

$$
\begin{aligned}
\leq & \text { CapCCE }+ \text { CapSCE }+ \text { CapAE }+ \text { CapKE }+ \text { Texp } * \text { CapCCN } \\
& + \text { TSCExp } * \text { CapSCN }+ \text { HExpA } * \text { CapAN }+H E x P R O R * \text { CapROR } \\
& +H \operatorname{HexpHiH} * \text { CapHiH }+ \text { CapKN } * \text { HexpK }+ \text { CAPPW } \\
& + \text { CAPSW } \\
& +E_{h} P W_{h} * 0.00023-\text { EsalWF }_{h} * 0.00023
\end{aligned}
$$

End of wet season constraints (conditional on state $w$ following state $h$ )

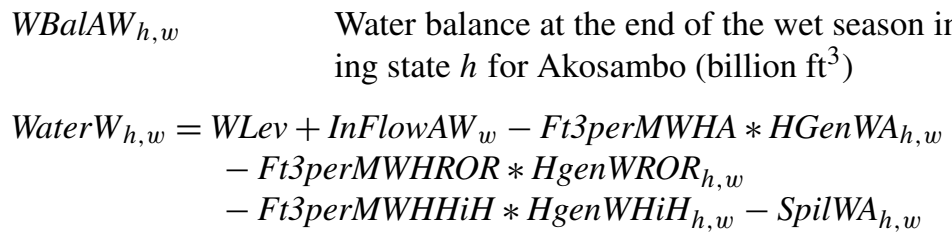

Water balance at the end of the wet season in state $w$ follow-

$W B a l K W_{h, w} \quad$ Water balance at the end of the wet season in state $w$ following state $h$ for Kpong (billion $\mathrm{ft}^{3}$ ) 


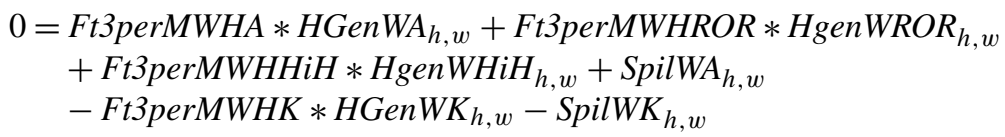

$\mathrm{EBalW}_{h, w}$

Electricity balance at the end of the wet season in state $w$ following state $h$ (thousand MWh)

$\operatorname{Dem}_{h, w}=$ TGenWSC $_{h, w}+$ TGenWCC $_{h, w}+\mathrm{HGenWA}_{h, w}$

$$
\begin{aligned}
& +\operatorname{HgenWROR}(h, w)+\operatorname{HgenWHiH}(h, w)+\operatorname{HGenWK}(h, w) \\
& +\operatorname{EPurWNF}(h, w)-\operatorname{ESalWNF}(h, w)+\operatorname{EPurWF}(h) \\
& -\operatorname{EsalWF}(h)+\operatorname{DistW}(h, w)+\operatorname{UnMDW}(h, w)
\end{aligned}
$$

GBalW $_{h, w}$

Gas balance at the end of the wet season in state $w$ following state $h$ (trillion Btu)

BtuperMWHSC $*$ TGenWSC ${ }_{h, w}+$ BtuperMWHCC $*$ TGenWCC $_{h, w}$

$=F G a s W_{h}+G P u r W_{h, w}-G S a l W_{h, w}$

MaxGen $W_{h, w} \quad$ Limit on generation for combined cycle during wet season in state $w$ following state $h$ (thousand MWh)

TGenWCC $_{h, w} \leq(\operatorname{CapCCE}+\operatorname{CapCCN} *$ TExp $) *$ HoursW

MaxGenWSC $C_{h, w} \quad$ Limit on generation for simple cycle during wet season in state $w$ following state $h$ (thousand MWh)

TGenWSC $_{h, w} \leq(\operatorname{CapSCE}+\operatorname{CapSCN} *$ TSCExp $) *$ HoursW

MaxGenWA $A_{h, w} \quad$ Limit on Akosambo generation in wet season in state $w$ following state $h$ (thousand MWh)

$H$ HenWA $_{h, w} \leq(\operatorname{CapAE}+\operatorname{CapAN} * H \operatorname{ExpA}) * H o u r s W$

MaxGenWROR $\mathrm{R}_{h, w} \quad$ Limit on ROR generation in wet season in state $w$ following state $h$ (thousand MWh)

$H_{\text {genWROR }}, w \leq \operatorname{HexpROR} *$ CAPROR $*$ HoursW

MaxGen $\mathrm{WHiH}_{h, w} \quad$ Limit on High head generation in wet season in state $w$ following state $h$ (thousand MWh)

$\mathrm{HgenWHiH}_{h, w} \leq \mathrm{HexpHiH} * \mathrm{CAPHiH} *$ HoursW

MaxGenWK $K_{h, w} \quad$ Limit on Kpong generation in wet season in state $w$ following state $h$ (thousand MWh)

$H G e n W K_{h, w} \leq(\operatorname{CapKE}+\operatorname{CapKN} * H E x p K) * H o u r s W$

MaxGas $W_{h, w} \quad$ Limit on wet season gas use set by pipeline capacity in state $w$ following state $h$ (trillion Btu)

FGas $_{h}+$ GPurW $_{h, w} \leq$ CapPipe

GSpotLim $W_{h, w} \quad$ Gas spot sales cannot exceed gas spot purchases in state $w$ following state $h$ (trillion Btu)

GSalW $_{h, w} \leq$ Fgas $_{h}$ 
TransCapWP $P_{h, w} \quad$ Transmission capacity in the wet season limits purchases in state $w$ following state $h$ (thousand MWh)

$\mathrm{EPurWF}_{h}+\mathrm{EPurWNF}_{h, w} \leq(\operatorname{CapTrE}+\operatorname{CapTrN} * \operatorname{TrExp}) * \operatorname{Hours} W$

TransCapWS $S_{h, w} \quad$ Transmission capacity in the wet season limits sales in state $w$ following state $h$ (thousand MWh)

$E S a l W N F_{h, w}+E_{S a l W F} \leq(\operatorname{CapTrE}+\operatorname{Cap} \operatorname{Tr} N * \operatorname{TrExp}) * H o u r s W$

PeakDbalD $_{h, w} \quad$ Capacity balance for the dry season in state $w$ following state $h$ (thousand MW)

PeakDD $D_{h, w} *$ ResMar

$$
\begin{aligned}
\leq & \text { CapCCE + CapSCE + CapAE + CapKE + Texp } * \text { CapCCN } \\
& + \text { TSCExp } * \text { CapSCN }+H E x p A * C a p A N+H E x p R O R * C a p R O R \\
& +H \operatorname{expHiH} * \text { CapHiH }+ \text { CapKN } * H \exp K+C A P P W(h)-C A P S W(h) \\
& +\operatorname{EPurDF}_{h, w} * 0.00023-\operatorname{EsalDF}_{h, w} * 0.00023
\end{aligned}
$$

Dry season constraints

WBalAD $D_{h, w}$

Water balance at the end of the dry season in state $d$ following state $w$ following state $h$ for Akosambo (billion $\mathrm{ft}^{3}$ )

WaterD $_{h, w, d}=$ Water $_{h, w}+\operatorname{InFlowAD} D_{w, d}-$ Ft3perMWHA $* H G e n D A_{h, w, d}$

- Ft3perMWHROR $*$ HenDROR ${ }_{h, w, d}$

- Ft3perMWHHiH $* \mathrm{HgenDHiH}_{h, w, d}-\mathrm{SpilDA}_{h, w, d}$

$W B a l K D_{h, w, d} \quad$ Water balance at the end of the dry season in state $d$ following state $w$ following state $h$ for Kpong (billion $\mathrm{ft}^{3}$ )

$0=$ Ft3perMWHA $* H G e n D A_{h, w, d}+$ Ft3perMWHROR $* H_{g e n D R O R}, w, d$

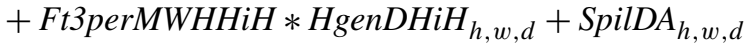

- Ft3perMWHK $* H G e n D K_{h, w, d}-S_{\text {PilDK }}, w, d$

$E B a l D_{h, w, d} \quad$ Electricity balance at the end of the dry season in state $d$ following state $w$ following state $h$ (thousand MWh)

$\operatorname{DemD}_{h, w, d}=$ TGenDSC $_{h, w, d}+$ TGenDCC $_{h, w, d}+$ HGenDA $_{h, w, d}$

$$
\begin{aligned}
& +\operatorname{HgenDROR}_{h, w, d}+\operatorname{HgenDHiH}_{h, w, d}+\text { HGenDK }_{h, w, d} \\
& + \text { EPurDNF }_{h, w, d}-\text { ESalDNF }_{h, w, d} \\
& + \text { EPurDF }_{h, w}-\text { EsalDF }_{h, w}+\text { Dist }_{h, w, d}+\operatorname{UnMDD}_{h, w, d}
\end{aligned}
$$

$G_{B a l D}, w, d \quad$ Gas balance at the end of the dry season in state $d$ following state $w$ following state $h$ (trillion Btu)

BtuperMWHSC $*$ TGenDSC $C_{h, w, d}+$ BtuperMWHCC $*$ TGenDCC $_{h, w, d}$ $=F G a s D_{h, w}+$ GPurD $_{h, w, d}-$ GSalD $_{h, w, d}$

MaxGenDCC $C_{h, w, d} \quad$ Limit on generation for combined cycle during dry season in state $d$ following state $w$ following state $h$ (thousand MWh)

$\operatorname{TGenDCC}_{h, w, d} \leq(\operatorname{CapCCE}+\operatorname{CapCCN} * \operatorname{TExp}) *$ HoursD

MaxGenDSC $C_{h, w, d} \quad$ Limit on generation for simple cycle during dry season in state $d$ following state $w$ following state $h$ (thousand MWh) 
$\operatorname{TGenDSC}_{h, w, d} \leq(\operatorname{CapSCE}+\operatorname{CapSCN} *$ TSCExp $) *$ HoursD

MaxGenDA $A_{h, w, d} \quad$ Limit on Akosambo generation in dry season in state $d$ following state $w$ following state $h$ (thousand MWh)

$H_{G e n D A}, w, d \leq(\operatorname{CapAE}+\operatorname{CapAN} * H \operatorname{Exp} A) * H o u r s D$

MaxGenDROR $R_{h, w, d} \quad$ Limit on ROR generation in dry season in state $d$ following state $w$ following state $h$ (thousand MWh)

$H_{G e n D R O R}, w, d \leq H \operatorname{expROR} * C A P R O R * H o u r s D$

MaxGenDHiH $H_{h, w, d} \quad$ Limit on High head generation in dry season in state $d$ following state $w$ following state $h$ (thousand MWh)

$H \mathrm{GenDHiH}_{h, w, d} \leq \mathrm{HexpHiH} * \mathrm{CAPHiH} * \mathrm{HoursD}$

MaxGenDK $K_{h, w, d} \quad$ Limit on Kpong generation in dry season in state $d$ following state $w$ following state $h$ (thousand MWh)

$H G e n D K_{h, w, d} \leq(\operatorname{CapKE}+\operatorname{CapKN} * H \operatorname{ExpK}) * H o u r s D$

MaxGas $D_{h, w, d} \quad$ Limit on dry season gas use set by pipeline capacity in state $d$ following state $w$ following state $h$ (trillion Btu)

FGasD $D_{h, w}+$ GPurD $_{h, w, d} \leq$ CapPipe

GSpotLimD $_{h, w, d} \quad$ Gas spot sales cannot exceed gas spot purchases in the dry season in state $d$ following state $w$ following state $h$ (trillion Btu)

GSalD $_{h, w, d} \leq F G a s D_{h, w}$

TransCapDP $P_{h, w, d}$ Transmission capacity in the dry season limits purchases in state $d$ following state $w$ following state $h$ (thousand MWh)

$\operatorname{EPurDF}_{h, w}+\mathrm{EPurDNF}_{h, w, d} \leq(\operatorname{CapTrE}+\operatorname{CapTrN} * \operatorname{TrExp}) *$ HoursD

TransCapDS $S_{h, w, d} \quad$ Transmission capacity in the dry season limits sales in state $d$ following state $w$ following state $h$ (thousand MWh)

$E_{\text {SalDNF }}{ }_{h, w, d}+$ ESalDF $_{h, w} \leq(\operatorname{Cap} \operatorname{TrE}+\operatorname{Cap} \operatorname{TrN} * \operatorname{TrExp}) * H o u r s D$

Sustain $_{h, w, d} \quad$ Expected ending water must equal beginning water in state $d$ following state $w$ following state $h$ (billion $\mathrm{ft}^{3}$ )

WaterD $_{h, w, d}=$ WLev

Objective function

TCost

Cost objective (million USD)

ECost $=$

\{Cost of capacity investments

(CostCapCCN $*$ TExp + CostCapAN $*$ HExpA

$+\mathrm{COSTCAPROR} * \mathrm{HexpROR}+\mathrm{COSTCAPHiH} * \mathrm{HexpHiH}$ 
$+\operatorname{CostCapKN} * \operatorname{HExpK}+\operatorname{CostCapTrN} * \operatorname{TrExp}+\operatorname{CostCapSCN} * \operatorname{TSCExp}$

+ CostFill $*($ WLev - WLevNow $)) * C R F$

\{At beginning of wet season\}

$+\sum_{h}\left[\operatorname{Prh}_{h} *\left(\left(P F G a s W_{h} * F G a s W_{h} *\right)\right.\right.$

$+\operatorname{CostCAPPW_{h}} * C A P P W_{h}-\operatorname{RevCaps}_{h} * C A P S W_{h}$

$+\mathrm{PEPurWF}_{h} * \mathrm{EPurWF}_{h}-\mathrm{PEsalWF}_{h} * \mathrm{EsalWF}_{h}$

\{During wet season\}

$+\sum_{w, d}\left[\right.$ Prwd $_{w, d} *\left(\left(P G P u r W_{h, w} *\right.\right.$ GPurW $_{h, w}-$ PGSalW $_{h, w} *$ GSalW $_{h, w}$

+ PEPurWNF $_{h, w} *$ EPurWNF $_{h, w}-$ PESalWNF $_{h, w} *$ ESalWNF $\left._{h, w}\right)$

$+P U M D * U n M D W_{h, w}+P \operatorname{Dist} W_{h, w} * \operatorname{Dist} W_{h, w}$

\{At beginning of dry season\}

$+\left(\right.$ PFGas $_{h, w} *$ FGasD $\left._{h, w}\right)+$ PEPurDF $_{h, w} *$ EPurDF $_{h, w}$

$-P E S a l D F_{h, w} * E_{S a l D F} F_{h, w}$

\{During dry season\}

$+\left(\right.$ PGPurD $_{h, w, d} *$ GPurD $_{h, w, d}-$ PGSalD $_{h, w, d} * G_{\text {SalD }}, w, d$

+ PEPurDNF $_{h, w, d} *$ EPurDNF $_{h, w, d}$

- PESalDNF PE,w,d $*$ ESalDNF $\left._{h, w, d}\right)+$ PDistD $_{h, w, d} *$ DistD $_{h, w, d}$

$\left.\left.\left.\left.\left.+P U M D * U n M D D_{h, w, d}\right)\right)\right)\right]\right]$

Bounds on variables

WLev $\geq$ PenstockWL

WLev $\leq$ StorCap

Water $_{h, w} \leq$ StorCap

WaterD $_{h, w, d} \leq$ StorCap

Dist $W_{h, w} \leq$ CapDist $*$ HoursW

DistD $_{h, w, d} \leq$ CapDist $*$ HoursD

$H \operatorname{Exp} A \leq 6$

$H \operatorname{expROR}=0$

$\mathrm{HexpHiH}=0$

SpilWA $_{h, w}=0$

SpilDA $_{h, w, d}=0$

$H \operatorname{Exp} K \leq 10$

$T \operatorname{Exp} \leq 20$

TSCExp $\leq 20$

$\operatorname{TrExp} \leq 20$

Wlev $=3209$

Changes needed to implement run of river with the model above.

Constraints

Water $W_{h, w}=$ Wlev $\quad$ Water level must be the same as the initial level at the end of the wet season regardless of inflows 


\section{Variable bounds}

SpilWA $_{h, w}>=0$

SpilDA $_{h, w, d}>=0$

Dealing with the non-linear water balance equation

As was mentioned previously, the water balance equation contains a term consisting of the product of two variables - the productivity $\left(\mathrm{ft}^{3} / \mathrm{KWh}\right)$ of the Akosombo turbines, and the KWh of electricity generated by the Akosombo turbines. This causes trouble for any linear integer program routine.

The productivity term is assumed to be primarily a function of the initial volume in the Akosombo reservoir, a variable decided in Stage I of the model. This function is assumed to be a rectangular hyperbolic function in the first quadrant, truncated at the maximum and minimum reservoir volumes, and is approximated by a three piece-wise linear function in the program, as discussed above. More segments would likely result in lower estimates of the water needed to generate a given amount of electricity at given lake levels, since piecewise linear approximations of the function constructed by connecting available data points on a rectangular hyperbola in the first quadrant will always lie above the exact function. This means the approximate function will overstate the amount of water required to generate a $\mathrm{kWh}$ of electricity for any given reservoir level. The electricity generated by the Akosombo turbines is decided in Stage II of the program.

This non-linearity in the model is handled in the following way. First, using an initial estimate for water productivity, the problem is solved, and the optimal water volume recorded for that water productivity value. That water volume is then compared to the water volume which satisfies the rectangular hyperbolic relationship between water volume and the assumed initial water productivity, and the water productivity value is then adjusted up, if the value is lower than the function value, or down, if greater than the function value. The process repeated until a pair of productivity/ volume numbers are found which satisfy the hyperbolic relationship. Convergence is assured because of the convexity of the hyperbolic relationship.

\section{References}

1. Andah, W.E.I, van de Giesen, N., Biney, C.A.: Water, climate, food, and environment in the Volta basin. ADAPT

2. BC Hydro News Release: BC hydro files revenue requirements application with BCUC. BC Hydro News Release, February 20. http://bchydro.com/news/articles/press_releases/2008. Accessed: $<$ Tom - Date needed here.> (2008)

3. Conner, A.M., Francfort, J.E., Rinehart, B.N.: U.S. hydropower resource assessment final report. Idaho National Engineering and Environmental Laboratory, Idaho Falls, Idaho, December. http:// www1.eere.energy.gov/windandhydro/pdfs/doewater-10430.pdf. Accessed on November 19, 2009 (1998)

4. Edwards, B.K., Flaim, S.J., Howitt, R.E.: Optimal provision of hydroelectric power under environmental and regulatory constraints. Land Econ. 75(2), 267-283 (1999)

5. EIA: Natural gas navigator, natural gas prices, May. http://tonto.eia.doe.gov/dnav/ng/ng_pri_sum_ dcu_nus_m.htm. Accessed on November 19, 2009

6. Emmet, J.D.: Network stochastic programming for valuing reservoir storage. MS thesis, University of Colorado (2002) 
7. ENR: $\$ 300$ Million Turbine Order Launches $\$ 1$ Billion Program. ENR.com, August 13, 2008. http:// enr.ecnext.com/coms2/article_nepoar080813c. Accessed on November 19, 2009

8. EPRI: Program on technology innovation: integrated generation technology options. Energy Technology Assessment Center Document No. 1018320, Technical Update, Electric Power Research Institute, Palo Alto, California, November (2008)

9. Farrell, M.B.: Klamath river dam removal project will be the World's biggest. Christ. Sci. Monit. Sept 30, 2009

10. Guan, X., Svoboda, A., Li, C.-A.: Scheduling hydro power systems with restricted operating zones and discharge ramping rates. IEEE Trans. Power Syst. 14(1), 126-131 (1999). doi:10. $1109 / 59.744500$

11. Harpman, D.A.: Assessing the short-run economic cost of environmental constraints on hydropower operations at Glen Canyon dam. Land Econ. 75(3), 390-401 (1999). http://www.jstor.org/stable/ 3147185. Accessed on November 19, 2009

12. Homa, E.S., Vogel, R.M., Smith, M.P., Apse, C.D., Huber-Lee, A., Seiber, J.: An optimization approach for balancing human and ecological flow needs. In: Proceedings of the EWRI 2005 World Water and Environmental Resources Congress, ASCE, Anchorage, Alaska, pp. 2-12 (2005). http:// engineering.tufts.edu/cee/people/vogel/publications/optimization.pdf. Accessed on November 19, 2009

13. International Rivers: About dams. Fact Sheet www.internationalrivers.org/en/node/287 (2010)

14. Jager, H.I., Smith, B.T.: Sustainable reservoir operation: can we generate hydropower and preserve ecosystem values? River Res. Appl. 24(3), 340-352 (2008). doi:10.1002/rra.1069

15. Kotchen, M.J., Moore, M.R., Lupi, F., Rutherford, E.S.: Environmental constraints on hydropower: an ex post benefit cost analysis of dam relicensing in Michigan. Land Econ. 82(3), 384-403 (2006). http://le.uwpress.org/cgi/reprint/82/3/384. Accessed on November 19, 2009

16. Luenberger, D.G.: Investment Science. Oxford University Press, New York (1998)

17. Manne, A.S.: Capacity expansion and probabilistic growth. Econometrica, 29(4), 632-649 (Oct 1961)

18. Mount Holyoke: China's Three Gorges dam; social consequences of relocation. www.mtholyoke.edu/ vanti20m/classweb/website (2011)

19. Pindyck, R.S.: The dynamics of commodity spot and future markets: a primer. Energy J. 22(3), 1-30 (2001)

20. Poff, N.L., Allan, J.D., Bain, M.B., Karr, J.R., Prestegaard, K.L., Richter, B.D., Sparks, R.E., Stromberg, J.C.: The natural flow regime a paradigm for river conservation and restoration. Bioscience 47(11), 769-784 (1997)

21. Preckel, P.V., Sparrow, F.T., Bowen, B.H., Yu, Z., Gotham, D.J., Yang, R.Z.: Preserving low cost electricity while improving the riverine environment: a case study of Ghana's Akosombo dam complex. Presented at the IEEE Power Engineering Society General Meeting, Pittsburgh, Pennsylvania, July 23, 2008, pp. 1-6. doi:10.1109/PES.2008.4596426

22. Preckel, P.V., Sparrow, F.T., Bowen, B.H., Yu, Z., Gotham, D.J.: Preserving low cost electricity while improving the riverine environment: part two-model results. Presented at the IEEE Power Engineering Society General Meeting, Pittsburgh, Pennsylvania, Calgary, Alberta, July 26-30, 2009. doi:10. 1109/PES.2009.5275433

23. Sale, M.J., Brill, J.E.D., Herricks, E.E.: An approach to optimizing reservoir operation for downstream aquatic resources. Water Resour. Res. 18, 705-712 (1982)

24. Taylor, W.T., Braymer, D.H.: American Hydroelectric Practice. McGraw-Hill, New York (1917). Updated to present costs

25. U.S. Army Corps of Engineers, Libby units \#6-8 evaluation report. Water Management Division, North Pacific Division, U.S. Army Corps of Engineers (August 1994)

26. USSD: Policy statement. United States Society on Dams, Committee on Dam Decommissioning (2011)

27. World Commission on Dams: "Flushing of sediments from reservoirs", Dr. Rodney W. White, H.R. Wallingford, UK, Prepared for Thematic Review V.5, Operation, Monitoring, and Decommission of Dams (2000) 